\title{
Implicações da vivência de prisão preventiva por violência conjugal: narrativas masculinas
}

\author{
Implications of the experience of preventive detention for intimate partner \\ violence: male narratives (abstract: p. 12)
Implicaciones de la vivencia de prisión preventiva por violencia conyugal: narrativas masculinas (resumen: p. 12)

\author{
Andrey Ferreira da Silva(a) \\ <silva.andrey1991@hotmail.com> \\ Nadirlene Pereira Gomes ${ }^{(b)}$ \\ $<$ nadirlenegomes@hotmail.com>
}

Fernanda Matheus Estrela ${ }^{(\mathrm{c})}$

$<$ nanmatheus@yahoo.com.br>

Josinete Gonçalves dos Santos Lírio(d)

<josilirio@hotmail.com>

Vera Lúcia de Azevedo Lima(e)

$<$ veraluci@ufpa.br>

Álvaro Pereira(f)
<alvaro_pereira_ba@yahoo.com.br>

\section{Artigos}

Objetiva-se conhecer as implicações da vivência de prisão preventiva por meio da história oral de homens em processo criminal por violência conjugal. Utilizou-se a história oral temática, sendo realizadas entrevistas semiestruturadas com 11 homens em processo criminal por violência conjugal que vivenciaram a prisão preventiva, residentes em Belém, Pará, Brasil, nos meses de junho e julho de 2015. Os dados foram organizados e categorizados segundo análise de conteúdo temática categorial. As narrativas masculinas despontaram para: implicações físicas e psíquicas, comprometimento de interação social, expressos pela exclusão familiar, problemas financeiros e dificuldade de empregabilidade. A análise das implicações da experiência de prisão preventiva permite refletir acerca da importância da articulação intersetorial, implementação de espaços reflexivos e discussões no campo das desigualdades de gênero.

Palavras-chave: Violência por parceiro íntimo. Gênero. Masculinidades. Aplicação da Lei. Saúde do homem. 


\section{Introdução}

A violência contra a mulher consiste em um fenômeno complexo, legitimado nas construçôes sociais, que naturaliza o poder do masculino sobre o feminino, com sérias implicações socioeconômicas para toda a sociedade. Nestas, encontram-se os danos sobre a saúde física e mental de toda a família, inclusive dos próprios homens.

Os altos índices de violência contra a mulher podem ser evidenciados em pesquisas, a exemplo dos Estados Unidos e Brasil, cuja prevalência de agressão pelo parceiro íntimo equivaleu de 4,7 a 17 para cada cem mulheres, respectivamente relacionados à violência física alguma vez na vida ${ }^{1}$.

Estima-se que cerca de quarenta mil brasileiras buscam o Sistema Único de Saúde (SUS) para tratamentos devido à violência, representando um custo anual superior a cinco milhôes de reais ${ }^{2}$. Todavia, esse valor não representa o gasto real do setor saúde, visto que se limita aos registros de internamentos associados ao agravo, não necessariamente contemplando demandas que a população feminina busca, por exemplo, quando se direcionam a serviços da Atenção Primária à Saúde (APS) 3 .

Estudos revelam ainda o abuso no qual as mulheres que vivenciam a violência no cotidiano doméstico estão expostas, incluindo ameaças de morte, bem como a dificuldade de romper esse ciclo em um contexto permeado pela baixa autoestima, tristeza, medo e depressão, além de isolamento social e não qualificação para o mercado de trabalho, visto que abandonaram os estudos para cuidar da casa, dos filhos e do marido ${ }^{4,5}$. Tal panorama sinaliza para custos com outros serviços da rede de atenção a pessoas em situação de violência, os quais envolvem, além do setor saúde: as áreas sociais, policiais, jurídicas, de educação, dentre outras.

Assim como estes gastos, aqueles referentes aos danos do agravo aos demais membros da família, incluindo filhos e o cônjuge ${ }^{4,6}$, também não vêm sendo contemplados financeiramente. No que tange às crianças, estudos alertam que presenciar a violência entre os pais relaciona-se ao comprometimento no rendimento escolar e a vulnerabilidade para o uso de drogas $\mathrm{s}^{4,7}$. Além disso, pessoas com histórico de abusos familiares na infância e/ou adolescência tendem a reproduzi-la nas relações interpessoais, favorecendo a intergeracionalidade da violência doméstica, onde se insere a conjugal ${ }^{8,9}$.

O processo de construção da assimetria de gênero, que naturaliza a dominação do homem sobre a mulher, é evidenciado na história das relações humanas, consolidando os modelos hegemônicos de masculinidade pautados no patriarcado ${ }^{10}$. Isso porque ser homem, em uma sociedade machista e falocêntrica, encontra-se fincado em valores e atributos, como ser o provedor, corajoso, viril, forte e, inclusive, violento ${ }^{11}$. Diante do exposto, não podemos desconsiderar a reprodução social do homem-cônjuge-agressor.

Reconhecendo que coibir a violência doméstica e familiar contra a mulher perpassa pela desconstrução da masculinidade hegemônica, a Lei brasileira n. 11.340/2006 preconiza, para além da prisão preventiva de homens autores de violência, a sua participação em programas de recuperação e reeducação por meio de atividades reflexivas, educativas e pedagógicas como forma de assegurar a proteção da mulher e/ ou filhos ${ }^{12}$. Incentivados legalmente, os grupos reflexivos com homens configuramse enquanto estratégias para sensibilizá-los e responsabilizá-los quanto ao caráter criminoso de seus atos, bem como pensar medidas pacíficas para a resolução dos conflitos conjugais ${ }^{13}$. 
Nesse sentido, Programas ingleses defendem que as intervenções transformadoras de gênero e masculinidades podem ser eficazes no sentido de reduzirem a perpetração da violência ${ }^{13,14}$. No âmbito nacional, estudos revelam que existem vinte estados que possuem Grupos e Programas de atendimento a homens autores e em situação de violência conjugal no Brasil, e sete estados com grupos de estudos sobre homens em situação de violência contra a Mulher .

Por darem vozes aos homens, estes espaços também vêm dando visibilidade aos danos da violência conjugal sobre suas vidas, como: cefaleia, diarreia, estresse e depressão, conforme oralidades de 229 homens em processo de prisão preventiva no Rio Grande do Norte ${ }^{15}$.

Considerando que, assim como as mulheres, os homens são sócio-historicamente construídos para reproduzirem a violência conjugal, agravo que também lhes trazem prejuízos e oneram ainda mais os custos do país com a problemática, o estudo objetiva: conhecer as implicaçóes da vivência de prisão preventiva por meio da história oral de homens em processo criminal por violência conjugal.

\section{Metodologia}

Trata-se de uma pesquisa de abordagem qualitativa, fundamentada na História Oral. Utilizou-se a modalidade história oral temática como referencial metodológico, por permitir desvelar as versões, interpretaçôes e experiências vivenciadas, e assim fornecer elementos sobre o fenômeno vivido de acordo com a individualidade dos participantes do estudo ${ }^{16}$.

O estudo foi realizado no município de Belém, Pará, Brasil. Os participantes da pesquisa foram 11 homens que estavam em processo criminal por violência conjugal, que experienciaram a prisão preventiva e participavam do Grupo Reflexivo (GR). A lei preconiza, em seu 20 o artigo, que, em qualquer fase do processo do inquérito policial, caberá a prisão preventiva do agressor decretada pelo juiz de ofício, a requerimento do Ministério Público ou mediante representação da autoridade policial. Quanto aos GR, estes foram realizados pelo Núcleo Especializado de Atendimento ao Homem Autor de Violência Doméstica e Familiar (NEAH), órgão parceiro da defensoria pública do estado, que se destina ao cumprimento do art. 35, em seu inciso V da Lei 11.340/2006, que versa pela recuperação e reeducação por meio de atividades reflexivas, educativas e pedagógicas.

A aproximação com os homens ocorreu mediante a autorização da coordenação do NEAH e acompanhamento de todo o processo de um GR pelo pesquisador principal. Após o término do ciclo de encontros, o convite a participar do estudo foi realizado mediante a informação do objetivo, relevância do estudo e o esclarecimento das questóes éticas a serem asseguradas, tais como o direito de optar por não participar da pesquisa, o de desistir em qualquer fase, sem que haja prejuízo no atendimento prestado pelo NEAH, bem como de ter sua identidade e informaçóes pessoais preservadas. Para tal, os homens foram identificados por meio da codificação alfanumérica ( $\mathrm{H} 1, \mathrm{H} 2, \ldots \mathrm{H} 11)$, utilizando-se a letra $\mathrm{H}$, seguida de numerais.

Todos os participantes do GR aceitaram colaborar com o estudo, sendo posteriormente agendados hora e local do encontro. Durante os encontros, realizouse a leitura do Termo de Consentimento Livre e Esclarecido e assinatura do mesmo 
pelos participantes para, posteriormente, dar-se início a coleta dos dados. Salienta-se que está pesquisa foi realizada mediante aprovação do Comitê de Ética em Pesquisa da Universidade Federal do Pará (UFPA), por meio do Parecer 1.091.031.

As entrevistas foram realizadas nos meses de junho e julho de 2015, utilizando um roteiro semiestruturado, elaborado pelo próprio pesquisador, que continha questóes sobre aspectos sociodemográficos (idade, religião, raça/cor, escolaridade, renda familiar) para fins de caracterização dos colaboradores, e a seguinte questão orientadora: Fale-me sobre as implicações da experiência de prisão preventiva para sua vida?

As narrativas tiveram duração média de trinta minutos, sendo gravadas e transcritas para a obtenção do corpus para análise. Todo o material empírico foi sistematizado com base na análise de conteúdo temática categorial proposta por Franco ${ }^{17}$, que orientou a organização dos conteúdos das mensagens apreendidas no texto, permitindo o surgimento das categorias. Assim, após a leitura flutuante, a exploração do material e a categorização dos dados, emergiram duas categorias temáticas, a saber: "Implicaçóes para a saúde física e mental”, tendo por subcategorias "danos à saúde física" e "danos à saúde psíquica”; e as "Implicaçốes socioeconômicas”, expressas no "isolamento social”, "problemas financeiros" e "dificuldades de empregabilidade". A interpretação dos achados respaldou-se nos referenciais de gênero e masculinidade hegemônica, com enfoque nas relações de poder e dominação e suas repercussóes no processo de saúde e adoecimento.

\section{Resultados}

Os colaboradores da pesquisa tinham entre 21 e 57 anos de idade. Se autodeclararam, em sua maioria: pardos, católicos, de baixa escolaridade, renda familiar de até dois salários-mínimos mensais, e motivo para prisão preventiva: a violência física como mostra a tabela 1 .

Tabela 1. Caracterização sociodemográfica e Motivação da Prisão Preventiva Dos Participantes da Pesquisa

$\begin{array}{ccc}\text { Participante } & \text { Idade } & \text { Raça/Cor } \\ \text { H1 } & 30 & \text { Pardo } \\ \text { H2 } & 34 & \text { Pardo } \\ \text { H3 } & 45 & \text { Pardo } \\ \text { H4 } & 26 & \text { Negra } \\ \text { H5 } & 57 & \text { Pardo } \\ \text { H6 } & 46 & \text { Negra } \\ \text { H7 } & 33 & \text { Negra } \\ \text { H8 } & 39 & \text { Branca } \\ \text { H9 } & 46 & \text { Pardo } \\ \text { H10 } & 39 & \text { Negra } \\ \text { H11 } & 22 & \text { Pardo }\end{array}$

Religião
Católica
Espirita
Católica
Católica
Umbanda
Católica
Evangélica
Católica
Evangélica
Católica
Católica

\section{Escolaridade}

Fundamental incompleto

Fundamental incompleto

Fundamental incomplet

Fundamental incompleto

Superior incompleto

Fundamental incompleto

Fundamental incompleto 1 salário- mínimo Médio incompleto 4 salários- mínimos

Fundamental incompleto 1 salário- mínimo

Médio completo 2 salários- mínimos

Fundamental incompleto 1 salário- mínimo
Motivo da prisão preventiva

Violência Física

Violência física e psicológica

Violência física e psicológica

Violência Física

Violência física

Violência Física

Violência física e psicológica

Violência Psicológica

Violência física e psicológica

Violência Física

Violência Física

Fonte: Pesquisa de Campo

As implicações da experiência de prisão preventiva, conforme narrativas dos participantes da pesquisa foram desveladas, conforme categorias a seguir. 


\section{Implicações para a saúde física e mental}

Com base na oralidade dos homens em situação de violência conjugal, as repercussóes do processo de prisão preventiva por violência conjugal, sobretudo aos casos relacionados a agressão física contra a mulher se expressaram a partir do comprometimento sobre a saúde fúsica e mental dos mesmos, conforme ilustram as seguintes subcategorias:

\section{Danos à saúde física}

A prisão preventiva, que experienciaram esses homens, desencadeou problemas de saúde de ordem física, a exemplo de: cefaleia, hipertensão, inapetência e problemas gastrointestinais.

“Ter sido preso preventivamente afetou minha saúde física. Eu não consigo me alimentar direito e quando me alimento, tenho desarranjo intestinal. [...] perdi peso, tive gastrite nervosa." (H.8)

“Depois da prisão preventiva, percebi que minha saúde está fragilizada. [...] minha pressão fica elevada, tenho dores de cabeça constante. Sinto um aperto no peito.” (H.2)

\section{Danos à saúde psíquica}

A narrativa masculina revelou que, experienciar a prisão preventiva por violência conjugal, se mostra enquanto evento gerador de adoecimento psicoemocional, manifesto pela hipervigilância, estresse, tristeza e depressão. Evidencia-se ainda a existência do medo de vivenciar novamente o processo de prisão.

"Depois que sair da prisão preventiva, comecei a me sentir muito estressado. Não consigo dormir; tenho pesadelos constantes. Passo o dia em estado de alerta. [...] quando vejo um carro da polícia, fico muito nervoso e com medo de ser preso novamente.” (H.4)

"Essa situação me deixou triste. Eu chorava todos os dias lembrando tudo que passei durante a prisão preventiva. [...] comecei a me sentir deprimido e desanimado. Não sentia vontade de sair de casa para nada. Passei a viver isolado.” (H.7)

\section{Implicações socioeconômicas}

Outras dimensôes das implicações da prisão preventiva, expressas na oralidade dos participantes, remetem a aspectos que comprometem as interaçóes sociais, inclusive de familiares, e o estabelecimento de suporte financeiro, conforme as subcategorias: 


\section{Isolamento social}

As relaçôes interpessoais de homens em situação de violência conjugal, de acordo com a narrativa masculina, são transformadas após a vivência de prisão preventiva, suscitando o isolamento social, com o afastamento de familiares, amigos e vizinhos.

"Após a prisão preventiva, meus familiares se afastaram. Minha mãe e meus irmãos não vão mais me visitar e toda vez que eu os procuro, eles me tratam mal e me isolam. Aos poucos, eu vou deixando de estar nas reunióes familiares." (H.8)

"Depois que saí da prisão preventiva, meus vizinhos passaram a comentar sobre o ocorrido e me olhavam de forma preconceituosa. [...] alguns amigos deixaram de falar comigo e, aos poucos, foram se afastando e eu fui me isolando socialmente." (H.3)

\section{Problemas financeiros}

A história oral da prisão, e consequentemente o não comparecimento aos espaços de trabalho, repercutiu diretamente em complicaçóes financeiras. Diante destas, os homens narraram recorrer à comercialização de utensílios domésticos e a solicitação de ajuda financeira de amigos.

"Quando saí da prisão preventiva, passei por muitas dificuldades financeiras: o serviço de fornecimento de luz e água para minha casa foi interrompido por falta de pagamento; tive que vender objetos de casa para conseguir dinheiro.” (H.1)

"Alguns amigos estão me ajudando financeiramente, pois, eu estou tento problemas financeiros por conta da dificuldade em conseguir um emprego." (H.8)

\section{Dificuldade de empregabilidade}

Para além dos escassos recursos financeiros, os homens entrevistados narravam a dificuldade de inserção no mercado de trabalho, relacionando-a à desconfiança dos empregadores em contratar pessoas com histórico de prisão.

"Depois que eu saí da prisão, tive dificuldades para conseguir um emprego. [...] quando as empresas verificavam que eu tinha sido preso, mesmo que de forma preventiva, não me davam oportunidade de trabalho.” (H.5)

"O homem que foi preso é muito prejudicado porque, após a prisão preventiva, as pessoas passam te olhar desconfiadas, principalmente em relação a trabalho. As empresas não me aceitam e eu perco oportunidades de emprego.” (H.6) 


\section{Discussão}

O perfil dos participantes da pesquisa desponta a necessidade de um enfoque em discussóes de classe e raça, visto que a maioria dos homens que experienciaram a prisão preventiva em decorrência de violência conjugal, se autodeclarava pardos e negros, e apresentava baixa escolaridade. A raça é apontada na literatura como uma variável a ser considerada diante da vivência de violência conjugal, visto as influências sócio-históricas que permeiam as relaçóes sociais no que se refere à população negra e parda, sendo tal condição vulnerabilizadora à essa população a sofrerem e a praticarem violência conjugal, levando, em sua maioria, homens negros a experienciarem a prisão preventiva ${ }^{18}$.

A baixa escolaridade também é apontada como fator catalisador de violência conjugal, o que resulta em desqualificação profissional, levando a inadequada remuneração salarial ou desemprego, dobrando a probabilidade de os homens praticarem violência física ou sexual ${ }^{19}$. Estudo evidencia que as questóes de classe e raça podem colaborar no esclarecimento social das relaçóes de poder, quando revelam que homens negros e pardos, de baixa escolaridade, aparecem como mais sujeitos à prisão por violência conjugal, uma vez que vivenciam uma história de vida marcada por desigualdades sociais, e relaçóes familiares marcadas por episódios de violência ${ }^{20}$.

As narrativas na abordagem da História Oral revelam que a experiência da prisão preventiva em decorrência de violência conjugal desponta para repercussóes de ordem físicas e comprometimentos para a vida dos homens, a exemplo do adoecimento físico. Falta de apetite, gastrite, diarreia, cefaleia e hipertensão foram implicaçôes desveladas no estudo. Tais achados são corroborados em pesquisas realizadas em Salvador e Rio Grande do Norte, que acrescentam outros sintomas físicos desencadeados pela vivência da prisão preventiva, tais como: emagrecimento, redução da força muscular e alteraçóes no padrão de sono ${ }^{6,15}$. No âmbito internacional, na Califórnia, o adoecimento físico dos homens em processo de prisão preventiva se manifestou por meio de hipertensão e problemas cardíacos ${ }^{21}$.

A interface entre a experiência de prisão preventiva e o adoecimento físico masculino guarda relação com os aspectos negativos rememorados e, portanto, revividos. É nesse contexto de resgate de momentos significativos que ocorre a somatização do vivido: a transferência para o corpo de problemas originados da esfera psicológica. Infere-se, portanto, que as doenças e queixas físicas apresentadas pelos homens relacionam-se, mais comumente, às situações estressantes do evento do que a existência de patologia orgânica, ainda que as condiçóes insalubres e de risco do cenário possam desencadear diversos adoecimentos. Assim, o adoecer dos homens sofre influência dos fenômenos psicossomáticos relacionados ao processo de prisão preventiva. Confirmando a somatização do processo de prisão preventiva por violência conjugal, estudo realizado nos Estados Unidos da América revela que esta vivência pode provocar o desenvolvimento de vários tipos de câncer e doenças crônicas ${ }^{22}$.

Sendo a doença psicossomática não exclusivamente corporal, visto que tem origem psíquica, a oralidade masculina revelou o adoecimento mental, expresso pela hipervigilância, tristeza, estresse e depressão. Tais achados encontram-se consonantes com estudo realizado no Rio Grande do Norte e na Bahia ${ }^{6,15}$. Pesquisa realizada na América do Norte desvela que o cerceamento de liberdade em delegacias e penitenciárias pode provocar depressão e Síndrome do Estresse Pós-Traumático 
(PTSD), podendo acarretar transtornos mentais graves e persistentes ${ }^{23} \cdot \mathrm{Na}$ Austrália, pesquisa realizada com homens portadores de sofrimento mental grave e persistente revelou que, geralmente, essas patologias estão associadas à experiência do encarceramento ${ }^{24}$.

Vale ressaltar que o estudo não estabelece a relação de causa-efeito entre ter experienciado a prisão preventiva e adoecer, todavia, faz referência entre o cerceamento da liberdade e o adoecimento psicossomático, sobretudo quando este rememora implicaçôes socioeconômicas da estigmatização que permeia os papéis sociais sobre expreso, o que intensifica o comprometimento sobre a saúde masculina. Corroborando, estudo aborda a existência de um papel vitimário para homens devido a condições da masculinidade que levam à própria impotência, sobretudo nesses casos. No entanto preferem atentar para a dinâmica das relaçôes e estrutura de poder, na qual insere-se a violência, que as fundamenta, deixando o homem bem distante do papel de vítima ${ }^{20}$.

Associado ao medo de ser recluso novamente, a oralidade masculina remete ao sentimento de nervosismo diante da presença de rondas policiais. Estudo realizado na Bahia revela que a experiência da prisão preventiva de homens em processo criminal por violência conjugal é marcada por episódios de violência e humilhação ${ }^{8}$. A realidade do ambiente carcerário apresenta obstáculos cotidianos, perpassando pela escassez de produtos alimentícios e de higiene, infraestrutura inadequada, violência entre os internos, tráfico de drogas e uso abusivo de drogas ilícitas ${ }^{25}$. Este cenário, que por si só justifica o trauma de revivê-lo, favorece o adoecimento físico e mental, intensificado pelos entraves que encontram quando retornam ao convívio social, sobretudo quando se trata da ressocialização do detento ${ }^{26}$.

O afastamento de familiares, amigos e vizinhos também foi uma implicação da prisão preventiva expressa na oralidade dos participantes do estudo. Pesquisa norteamericana corrobora com tais achados quando aponta que os homens que passaram pelo processo de reclusão sofrem atitudes preconceituosas que afetam seus laços sociais e familiares, tornando-os socialmente isolados ${ }^{27}$. Essa condição de retraimento é alimentada pela desconfiança social que se tem mediante a não credibilidade dada à recuperação de um ex-presidiário, o que guarda relação com a crença de que eles cometerão novos delitos, impedindo a construção de relaçóes de confiança e de vínculos empregatícios ${ }^{20,28,29}$.

Para além do isolamento social, a vivência do processo de prisão preventiva repercute diretamente na vida profissional dos homens, o que foi confirmado em estudo espanhol, ao revelar a dificuldade de reinserção no mercado no trabalho por parte desses sujeitos ${ }^{30}$. Assim sendo, a desestruturação financeira é apontada como resultado direto do processo de reclusão, relacionando-se à dificuldade do homem na empregabilidade ${ }^{28}$. Os obstáculos encontrados para conseguir emprego predispóem a dificuldade financeira, denotando a obrigatoriedade de vender bens materiais para obtenção de renda para sobreviver. Em meio a este cenário, os participantes recorreram a outras pessoas de seu convívio em busca de auxílio financeiro, conforme assinala pesquisa desenvolvida no Brasil, cujos ex-presidiários apelaram ao suporte social, como amigos e outros familiares, para conseguirem sustentar a família após saírem da prisão ${ }^{28}$. Em estudo norte-americano, este apoio foi evidenciado como positivo para a ressocialização de ex-detentos ${ }^{31}$. 
Vale referir que a prisão preventiva por violência conjugal é uma premissa cautelar, sem caráter condenatório, que objetiva o bom andamento do processo, bem como a eficácia das medidas protetivas para as mulheres, podendo ser revogada por meio de decisão judicial ${ }^{8}$, diferenciando-se do encarceramento penitenciário que clausura indivíduos julgados e condenados ${ }^{32}$. Todavia, o entendimento social equivocado de que tal medida protetiva tem o mesmo caráter condenatório nos permite compreender as narrativas masculinas de estigmatização sofrida, a qual repercute em dificuldades financeiras e de empregabilidade. Assim, para além do cerceamento provisório de sua liberdade, a vivência da prisão preventiva desencadeou a punição do estigma, que incita a deterioração de sua identidade coletiva e, consequentemente, o descrédito social. Importante salientar que a não ressocialização e o desemprego impossibilitam o resgate de sua dignidade enquanto ser humano ${ }^{29}$.

\section{Considerações finais}

Com base na oralidade masculina, a vivência de prisão preventiva compromete a saúde física e mental dos homens, provoca o isolamento social e desencadeia dificuldades financeiras e de empregabilidade. Embora limite-se por não estabelecer relação causa-efeito, o estudo sinaliza para a interface entre experienciar a prisão e o adoecimento psicossomático da lembrança do vivido e as implicaçốes socioeconômicas da estigmatização que permeia a visão social do ex-preso, que intensifica o comprometimento sobre a saúde masculina.

Considerando esses danos para a saúde e vida dos homens, bem como os custos direta e indiretamente relacionados às demandas para os diversos setores e áreas de conhecimentos, torna-se importante o direcionamento de medidas de tratamento e intervenção, sobretudo a partir de articulação intersetorial. Entendendo que tais danos se relacionaram ao evento da violência contra a mulher, é necessária, ainda, a promoção de espaços de reflexão, sobretudo no campo da saúde dos homens, com fins na qualidade de vida masculina, onde se insere o enfrentamento de questôes socioculturalmente apreendidas, como é o caso da violência conjugal.

O preconceito de ex-presos, emergido na história de vida dos participantes, nos conduz para a importância de programas sociais efetivos, sensíveis à necessidade financeira e afetiva da reinserção do indivíduo nas relações sociais e de trabalho. Essa temática, como a violência contra a mulher, são pautas que merecem e precisam ser constantemente debatidas com o recorte de gênero, visto os homens serem os principais envolvidos e estarem inseridos em um contexto sócio-histórico e cultural que reproduz e legitima o homem-dominador, vulnerabilizando-o para as implicaçóes desveladas nesse estudo.

Chama atenção para o fato de que, ao experienciar esse evento significativo, o homem rememora-o, somatizando a experiência traumática por meio do adoecimento, o qual é intensificado diante do preconceito em torno da imagem do ex-presidiário, ainda que a prisão tenho sido de caráter preventivo. No sentido de se evitarem os problemas psicossomáticos referentes à experiência de prisão, intensificando o adoecimento masculino, cabe-se pensar em propostas terapêuticas e/ou educativas que ajudem essas pessoas a ressignificarem a experiência dolorosa, o que pode ser contemplado, por exemplo, nos espaços de reeducação, preconizados pela Lei Maria da Penha. 


\section{Contribuições dos autores}

Todos os autores participaram ativamente de todas as etapas de elaboração do manuscrito.

\section{Direitos autorais}

Este artigo está licenciado sob a Licença Internacional Creative Commons 4.0, tipo BY (https://creativecommons.org/licenses/by/4.0/deed.pt_BR).

$(c c))^{\text {B }}$

\section{Referências}

1. Lindner SR, Coelho EBS, Bolsoni CC, Rojas PF, Boing AF. Prevalência de violência física por parceiro íntimo em homens e mulheres de Florianópolis, Santa Catarina, Brasil: estudo de base populacional. Cad Saude Publica. 2015; 31(4):815-26.

2. Waiselfisz JJ. Mapa da violência 2015: homicídio de mulheres no Brasil [Internet]. Brasília: Flacso Brasil; 2015 [citado 29 Set 2017]. v. 1. Disponivel em: http://www. mapadaviolencia.org.br/pdf2015/MapaViolencia_2015_mulheres.pdf

3. Gomes NP, Erdmann AL. Conjugal violence in the perspective of "Family Health Strategy" professionals: a public health problem and the need to provide care for the women. Rev Lat Am Enfermagem. 2014; 22(1):76-84. doi: 0104-1169.3062.2397.

4. Carneiro JB, Gomes NP, Estrela FM, Santana JD, Mota RS, Erdmann AL. Domestic violence: repercussions for women and children. Esc Anna Nery Rev Enferm. 2017; 21(4):e20160346.

5. Baena DM, Piñar IM, Agüir VE, Cases CV. Violence against young women attending primary care services in Spain: prevalence and health consequences. Fam Pract. 2015; $32(4): 381-6$.

6. Sousa AR, Pereira Á, Paixão GPN, Pereira NG, Campos LM, Couto TM. Repercussões da prisão por violência conjugal: o discurso de homens. Rev Lat Am Enfermagem. 2016; 24:e2847.

7. Magalhães JRF, Gomes NP, Mota RS, Campos LM, Camargo CL, Andrade SR. Intra-family violence: experiences and perceptions of adolescents. Esc Anna Nery Rev Enferm. 2017; 21(1):e20170003.

8. Paixão GPN, Gomes NP, Diniz NMF, Lira MOSC, Carvalho MRS, Silva RS. Women experiencing the intergenerationality of conjugal violence. Rev Lat Am Enfermagem. 2015; 23(5):874-9.

9. Metz C, Razon L. Marital violence and transgenerational transmission. What will become of the child witness? L'Evolution psychiatrique. 2015; 80(3):515-23. doi: 10.1016/j.evopsy.2014.11.001.

10. Rodrigues VP, Machado JC, Santos WS, Santos MFS, Diniz NMF. Violência de gênero: representaçóes sociais de familiares. Texto Contexto Enferm. 2016; 25(4):e2770015.

11. Wathen C, Nadine M, Jennifer CD, MacQuarrie BJ. The impact of domestic violence in the workplace: results from a Pan-Canadian survey. Int J Occup Med Environ Health. 2015; 57(7):65-71. 
12. Presidência da República (BR). Lei no 11.340 , de 7 de Agosto de 2006. Cria mecanismos para coibir a violência doméstica e familiar contra a mulher, nos termos do $\$ 8$ o do art. 226 da Constituição Federal, da Convenção sobre a Eliminação de Todas as Formas de Discriminação contra as Mulheres e da Convenção Interamericana para Prevenir, Punir e Erradicar a Violência contra a Mulher; dispõe sobre a criação dos Juizados de Violência Doméstica e Familiar contra a Mulher; altera o Código de Processo Penal, o Código Penal e a Lei de Execução Penal; e dá outras providências. Diário Oficial da União. 8 Ago 2006.

13. Muralidharan A, Fehringer J, Pappa S, Rottach E, Das M, Mandal M. Transforming gender norms, roles, and power dynamics for better health: evidence from a systematic review of gender-integrated health programs in low- and middle- income countries. Washington, DC: Futures Group; 2015.

14. Fleming PJ, Gruskin S, Rojo F, Dworkin SL. Men's violence against women and men are inter-related: recommendations for simultaneous intervention. Soc Sci Med. 2015; $146: 249-56$

15. Pinheiro MC, Araújo JL, Vasconcelos RB, Nascimento EG. Health profile of freedom-deprived men in the prison system. Investi Educ Enferm. 2015; 33(2):269-79.

16. Meihy J, Holanda F. História oral: como fazer, como pensar. 2a ed. São Paulo: Contexto; 2014.

17. Franco MLPB. Análise de conteúdo. 4a ed. Brasília: Liber Livro; 2012.

18. Gomes NP, Diniz NMF, Camargo CL, Silva MP. Homens e mulheres em vivência de violência conjugal: características socioeconômicas. Rev Gauch Enferm. 2012; 33(2):109-16.

19. Silva ACLG, Coelho EBS, Moretti-Pires RO. O que se sabe sobre o homem autor de violência contra a parceira íntima: uma revisão sistemática. Rev Panam Salud Publica. 2014; 35(4):278-83.

20. Oliveira PP. Discursos sobre a masculinidade. Estud Fem. 1998; 6(1):91.

21. Wildeman C, Lee H, Comfort M. A new vulnerable population? The health of female partners of men recently released from prison. Women's Health Issues. 2013; 23(6):e335-40.

22. Chareczko LL, Segal A, Perlis ML, Nowakowski S, Tal JZ, Grandner MA. Sleep disturbance partially mediates the relationship between intimate partner violence and physical/mental health in women and men. J Interpers Violence. 2017; 32(16):247195.

23. Birath C, Beijer U, DeMarinis V, af Klinteberg B. Women with substance abuse problems exposed to men's violence: a public mental health challenge. Pers Individ Dif. 2014; 60 Suppl:47.

24. Denton M, Foster M, Bland R. How the prison-to-community transition risk environment influences the experience of men with co-occurring mental health and substance use disorder. Aust N Z J Criminol. 2017; 50(1):39-55.

25. Andrade US, Ferreira FF. Crise no sistema penitenciário brasileiro: capitalismo, desigualdade social e prisão. Rev Psicol Diversidade Saude. 2015; 3(1):116-29.

26. Soares Filho MM, Bueno PMMG. Demografia, vulnerabilidades e direito à saúde da população prisional brasileira. Cien Saude Colet. 2016; 21(7):1999-2010.

27. Wilson NJ, Cordier R. A narrative review of Men's Sheds literature: reducing social isolation and promoting men's health and well-being. Health Soc Care Community. 2013; 21(5):451-63. 
28. Studart LMC. A reinserção social dos egressos do sistema prisional brasileiro: realidade ou utopia? Rev Episteme Transversalis. 2014; 6(1):78-92.

29. Rocha VFT, Lima TCB, Ferraz SFS, Ferraz SB. A Inserção do egresso do sistema prisional no mercado de trabalho: estudo de casos múltiplos em organizaçóes cearenses. Rev Pensamento Contemporaneo Adm. 2013; 7(4):185-207.

30. Hathazy P, Müller MM. The rebirth of the prison in Latin America: determinants, regimes and social effects. Crime Law Soc Change. 2016; 65(3):113-35.

31. Davis CP. Social support among releasing men prisoners with lifetime trauma experiences. Int J Law Psychiatry. 2014; 37(5):512-23.

32. Radeloff D, Lempp T, Kettner M, Rauf A, Kersten KB, Freitag CM. Male suicide rates in German prisons and the role of citizenship. PLoS One. 2017; 12(6):e0178959.

This study explored the implications of the experience of preventive detention drawing on the oral histories of men being prosecuted for intimate partner violence. The oral history of 11 men living in Belém, Brazil being prosecuted for intimate partner violence and who had experienced preventive detention were collected using semi-structured interviews conducted between June and July 2015. The data was organized and categorized using thematic content analysis. The male narratives revealed physical and psychological implications and impaired social interaction, expressed by family exclusion, financial problems, and difficulty in finding employment. The analysis of the implications of experiences of preventive detention provided valuable insights into the importance of intersectorality, the creation of reflective spaces, and discussions in the field of gender inequality.

Keywords: Intimate partner violence. Gender. Masculinities. Applying the law. Men's health.

Tiene el objetivo de conocer las implicaciones de la vivencia de prisión preventiva por medio de la historia oral de hombres en proceso criminal por violencia conyugal. Se utilizó la historia oral temática, realizándose entrevistas semiestructuradas con 11 hombres en proceso criminal por violencia conyugal que experimentaron la prisión preventiva, residentes en Belém, Estado de Pará, Brasil, en los meses de junio y julio de 2015. Los datos se organizaron y categorizaron según análisis de contenido temático de categoría. Las narrativas masculinas mostraron las implicaciones físicas y psíquicas, el compromiso de la interacción social, expresados por la exclusión familiar, problemas financieros y dificultad de condición para el empleo. El análisis de las implicaciones de la experiencia de prisión preventiva permite reflexionar sobre la importancia de la articulación intersectorial, implementación de espacios reflexivos y discusiones en el campo de las desigualdades de género.

Palabras clave: Violencia por parte de la pareja. Género. Masculinidades. Aplicación de la ley. Salud del hombre. 